\title{
Anesthesia for Off Pump Coronary Artery Bypass Surgery in a Patient with Brain Tumor
}

\author{
Sarwan K S Rawat', Battu Kumar Shrestha', Rajiv Juneja', Yatin Mehta', Naresh Trehan²
}

${ }^{1}$ Institute of Critical Care and Anesthesiology, Medanta the Medicity, Gurugram, India

${ }^{2}$ Heart Institute, Medanta the Medicity, Gurugram, India

Corresponding Author: Battu Kumar Shrestha

Department of Anesthesia, Shahid Gangalal National Heart Centre Kathmandu, Nepal

Email: battushrestha@gmail.com

ORCID ID NO: 0000-0002-7939-5951

Cite this article as: Rawat S. K. S., Shrestha B. K., Juneja R., et al. Anesthesia for Off Pump Coronary Artery Bypass Surgery in a Patient with Brain Tumor. Nepalese Heart Journal 2019; Vol 16 (2), 69-71

Submission date: $21^{\text {st }}$ May 2019

Accepted date: $18^{\text {th }}$ October 2019

\begin{abstract}
The outcome after off pump coronary artery bypass grafting (OPCAB) surgery has been promising. These good outcomes relate to the benefits of avoiding extra corporeal circulation. Some of the reported advantages include a lower incidence of renal complications, pulmonary complication, adverse neurological event, reduced transfusions requirement and attenuation of the systemic inflammatory response. If the patient has associated preoperative complicated neurological issues, then perioperative management will be more challenging and requires extensive care and precautions. We present a case with symptomatic meningioma and unstable angina who underwent successful urgent OPCAB surgery without further neurological deterioration.
\end{abstract}

Keywords: coronary artery bypass, meningioma, off pump.

DOI: https://doi.org/10.3126/njh.v16i2.26321

\section{Introduction}

Off-pump coronary artery bypass surgery (OPCAB) is newer approach to conventional on pump coronary artery bypass grafting. Main benefits of OPCAB are avoidance of deleterious effects of cardiopulmonary bypass associated inflammatory response leading to renal dysfunction, neurological complications, gastrointestinal stress and myocardial abnormalities ${ }^{1}$. Beside this it has economic advantage as well. OPCAB may be a better option for patients who have significant comorbid conditions that pose an unacceptable risk for cardiopulmonary bypass $(\mathrm{CPB})^{2}$. We present a case of symptomatic meningioma and unstable angina who underwent successful OPCAB.
The patient was 65 years diabetic, male, weighing $62 \mathrm{~kg}$ who presented with difficulty in walking for 3 years and memory disturbance for 2 years. He had history of seizures for one year. He was diagnosed as a case of Parkinsonism and was on medical therapy. He was admitted in our hospital for retrosternal chest pain and increasing shortness of breath for two days. On investigation his haemogram, liver function, thyroid function, renal function and coagulation profile were normal. Twelve lead electrocardiogram showed ischemic changes on anterolatral leads. Echocardiography reported regional wall motion abnormality on anterior and inferior wall with ejection fraction of $40 \%$. His coronary angiography showed triple vessel disease with left main stenosis of $50 \%$. His carotid doppler was normal and non contrast computed tomography of head showed olfactory groove meningioma. In view of left main disease with ongoing chest pain early cardiac revascularisation was planned. As the patient has significant preoperative neurological issues, he was scheduled for off pump coronary artery bypass. Patient was premedicated with lorazepam $2 \mathrm{mg}$ per oral in ward on night before surgery and morphine sulphate $5 \mathrm{mg}$ intramuscular

@ Nepalese Heart Journal. Nepalese Heart Journal retain copyright and works is simultaneously licensed under Creative Commons Attribution License CC - By 4.0 that allows others to share the work with an acknowledge of the work's authorship and initial publication in this journal

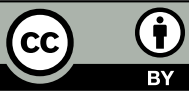


just before shifting to OT as per institutional protocol for high risk patients. Under local anesthesia peripheral venous cannula and 20 gauge left radial artery catheter were inserted. A $7.5 \mathrm{Fr}$ pulmonary artery catheter was floated through, introducer sheath in the right internal jugular vein. The mean pulmonary artery pressure was $23 \mathrm{~mm} \mathrm{Hg}$. Noninvasive monitoring included ECG, pulse oximetry, blood temperature, ETCO2, urine output and BIS (Bispectral Index). Anaesthesia was induced with intravenous thiopentone sodium $250 \mathrm{mg}$, fentanyl citrate 250 microgram, midazolam $2 \mathrm{mg}$,vecuronium bromide $10 \mathrm{mg}$. Trachea was intubated with $8.5 \mathrm{~mm}$ orotracheal tube. Anaesthesia was maintained with inhalation of isoflurane (1 to $2 \%$ ), oxygen and air, and incremental doses of fentanyl. Mechanical ventilation was given via closed circuit with tidal volume of $500 \mathrm{ml}$, respiratory rate 15 breaths per minute and PEEP $4 \mathrm{~cm}$ of $\mathrm{H} 2 \mathrm{O}$. Peak airway pressure remained between 15 to $20 \mathrm{~cm}$ of $\mathrm{H} 2 \mathrm{O}$. Left internal mammary artery (LIMA) was harvested. Heparin sulphate $2 \mathrm{mg} /$ $\mathrm{kg}$ was intravenously administered to achieve activated coagulation time (ACT) 300 seconds. On beating heart grafting was performed between LIMA to left anterior descending artery, saphenous vein to first obtuse marginal and posterior descending artery. During grafting his arterial blood gas and haemodynamic indices remained within normal limits with ionotropic support (norepinephrine, epinephrine), fluids administration. Trendelenberg or reverse trendelenberg position was avoided. Heart was stabilized with octopus tissue stabilizer (Medtronic Inc., Minneapolis, MN). After complete grafting heparin was reversed with protamine sulphate in dose of $2 \mathrm{mg} / \mathrm{kg}$. Patient was shifted to intensive care unit with stable hemodynamics and ABG. On post operative day 2 trachea was extubated after he met the extubation criteria indicating normal neurological status. Patient was shifted to the ward on post operative day 4. He was discharged from the hospital on sixth postoperative day and was readmitted after five weeks and endonasal endoscopic excision of olfactory groove meningioma was done under general anesthesia with uneventful recovery.

\section{Discussion}

There are two approaches of performing coronary artery bypass grafting $(\mathrm{CABG})$, conventional on pump CABG and newer OPCAB. The use of stabilization devices and intra-coronary shunts has helped to perform complete revascularization on a beating hearts without the need of cardiopulmonary bypass (CPB). It is estimated that $>80 \%$ of coronary revascularizations procedures can be performed as $\mathrm{OPCAB}$ with the largest reported series coming from the experiences of Benitti et al in Argentina ${ }^{3}$.

Meningiomas are slow growing tumors of brain. They are usually benign and may cause a slow increase in the intracranial pressure with mild or no symptoms for a long time. They are most common tumor associated with Parkinsonism. Brain tumors cause structural damage to the cerebral endothelium. They are associated with increased production of vascular endothelial growth factor, a potent angiogenic and peritumoraledema stimulant. When brain tumors are encountered in patients requiring cardiac surgery, the deleterious cerebral consequences of $\mathrm{CPB}$, such as impaired blood brain barrier and impaired cerebral autoregulation, may magnify the disturbances produced by the tumor itself $f^{4,5}$. CPB is associated with many adverse systemic effects like activation of systemic inflammatory response, neurocognitve dysfunction, coagulation abnormalities, myocardial and gastrointestinal dysfunctions ${ }^{6}$. Cerebral edema has been associated with normothermic and hypothermic $\mathrm{CPB}^{7}$. There is higher chances of embolization and nerurological injuries due to aortic cannulation during on pump surgery. Studies have shown that incidence of stroke after OPCAB is $1 \%$ as compared to $9 \%$ in on pump $\mathrm{CABG}^{8,9,10}$. So we chose OPCAB over on pump in this case.
Surgical priority was given to recent acute coronary syndrome over symptomatic intracranial pathology. There is no recommendation available for specific drugs or technique for induction in case of cardiac patients with brain tumor. We used sodium thiopentone as inducing agents because of its established neuroprotective effects ${ }^{[1]}$. All anaesthetic and vasoactive drugs were titrated to maintain stable hemodynamics and optimal cerebral perfusion. Adequacy of cerebral perfusion was also monitored with the use of NIRS. Ventilation was maintained to target $\mathrm{PaCO} 2$ of 30 to $35 \mathrm{mmHg}$. Trendelenberg position, which is often used to facilitate surgical exposure was deliberately avoided in this patient because of concerns about elevation of intracranial pressure (ICP). CVP was closely monitored as an indirect indicator of ICP. BIS monitoring was used to monitor precise titration of anaesthetic agents. It helps to facilitate earlier awakening and extubation, with early neurological assessment of the patient. Any sudden decrease in BIS readings unexplained by pharmacologic intervention or surgically induced hemodynamic instability could be a sign of intraoperative neurologic deterioration due to further rise in ICP or inadequate cerebral perfusion ${ }^{12}$. They may need hyperventilation, cautious fluid management and antiedema therapy such as with steroids and mannitol. Hyponatraemia or hypernatremia should be avoided.

In conclusion, coronary artery bypass surgery in presence of intracranial pathology may be challenging task for anesthesiologist. Increasing acceptance of $\mathrm{OPCAB}$ as revascularization techniques may be beneficial among the high risk patients.

\section{Sources of funding: None}

\section{Conflict of Interest: None}

\section{References}

1. Elahi MM, Khan JS, Matata BM. Deleterious effects of cardiopulmonary bypass in coronary artery surgery and scientific interpretation of off-pump's logic. Acute Card Care. 2006;8(4):196-209. DOI: 10.1080/17482940600981730

2. Prestipino F, Spadaccio C, Nenna A, et al. Off-pump coronary artery bypass grafting versus optimal medical therapy alone: effectiveness of incomplete revascularization in high risk patients. J Geriatr Cardiol. 2016 Jan; 13(1): 23-30. DOI: 10.11909/j.issn.1671-5411.2016.01.008

3. Benetti FJ, Naselli G, Wood M, et al. Direct myocardial revascularization without extracorporeal circulation: Experience in 700 patients. Chests. 1991; 100:312-316. DOI:10.1378/chest.100.2.312

4. Grigore AM, Grocott HP, Newman MF. Anesthetic management of a patient with a brain tumor for cardiac surgery. J CardiothoracVascAnesth 2000; 14: 702-4. DOI: 10.1053/jcan.2000.18442

5. Chakravarthy MR, Prabhakumar D. Anaesthesia for off pump coronary artery bypass grafting - the current concepts. Indian J Anaesth 2007; 51 (4): 334-343.

6. Murphy GJ, Angelini GD. Side effects of cardiopulmonary bypass: what is the reality? J Card Surg. 2004;19(6):481-8. DOI: $10.1111 /$ j.0886-0440.2004.04101.x

7. Harris DN, Oatridge A, Dob D, et al : Cerebral swelling after normothermic cardiopulmonary bypass. Anesthesiology 1998: 88:340-345. DOI: 10.1097/00000542-199802000-00011 
8. Trehan N, Mishra M, Sharma OP, et al. Furthur reduction in stroke after off pump coronary artery bypass grafting: A 10 year experi`ence. The Annals of Thoracic Surgery 2001; 72: 1026 - 1032. DOI:

https://doi.org/10.1016/S0003-4975(01)02936-8

9. Hirose H, Amano A. Stroke rate of off pump coronary artery bypass; aortocoronary bypass versus in-situ bypass. Angiology 2003; 54: 647 - 53. DOI: 10.1177/000331970305400603
10. Wang J, Gu C, Gao M, et al. Comparison of the incidence of postoperative neurologic complications after on-pump versus off-pump coronary artery bypass grafting in high-risk patients: A meta-analysis of 11 studies. Int. J. Cardiol. 2015; 185:195-97. https://doi.org/10.1016/j.ijcard.2015.03.115

11. Bilotta F, Stazi E, Zlotnik A, Gruenbaum SE, and Rosa G. Neuroprotective effects of intravenous anesthetics: A new critical perspective. Curr Pharm Des. 2014; 20(34): 5469-5475. DOI: $10.2174 / 1381612820666140325110113$ Myles PS.

Bispectral index monitoring in ischemic-hypoxic brain injury. $\mathrm{J}$ Extra Corpor Technol. 2009 Mar; 41(1): P15-P19 